\title{
A patient with recurrent hypothermia associated with thrombocytopenia
}

\author{
Kin Ming Chan and Keith Beard
}

Victoria Geriatric Unit, Mansionhouse Road, Langside, Glasgow G41 3DX, UK

\begin{abstract}
Summary: A 69 year old woman had 13 hospital admissions because of hypothermia attributed to self-neglect. On each occasion she was found to be thrombocytopenic, and the platelet count always returned to normal with rewarming. The case records of all patients admitted to the Victoria Infirmary between 1986 and 1990 with a primary diagnosis of hypothermia were reviewed. Two other patients of the 75 assessed were found to have had thrombocytopenia linked to hypothermia, but neither showed a recurrent relationship.
\end{abstract}

\section{Introduction}

Hypothermia is a problem with which doctors in temperate countries have to contend. Its neurological, psychiatric, circulatory, respiratory, hormonal, haematological and metabolic effects are well described. Among the haematological effects is thrombocytopenia, caused mainly by disseminated intravascular coagulation, cryoglobulinaemia or platelet sequestration. This last condition, previously described as hypothermia-induced thrombocytopenia, is rare and only a few case reports have been published over the past 25 years. ${ }^{1-4}$

We report a patient with no fewer than 13 admissions with hypothermia associated with thrombocytopenia. We also assessed the incidence of hypothermia-induced thrombocytopenia in a retrospective case record study.

\section{Case report}

A 69 year old woman was admitted to the Victoria Geriatric Unit, Glasgow because of confusion and hypothermia. On admission, she was drowsy and no history was available. Her rectal temperature was $31^{\circ} \mathrm{C}$, pulse rate was 60 per minute and blood pressure was $100 / 60 \mathrm{mmHg}$. Clinical examination revealed pallor, dehydration and a chronic varicose ulcer on her left leg. There was no hepatosplenomegaly or lymphadenopathy.

Investigations showed normochromic normocytic anaemia (haemoglobin $9.9 \mathrm{~g} / \mathrm{dl}$ ) and thrombocytopenia (platelet count $\left.12 \times 10^{9} / 1\right)$. The eryth-

Correspondence: K. Beard, F.R.C.P.

Accepted: 4 September 1992 rocyte sedimentation rate was $43 \mathrm{~mm}$ in the first hour. Serum urea and electrolytes, liver function tests, thyroid function tests, and coagulation studies were all normal. Tests for viral antibodies and auto-antibodies were negative. The electrocardiogram showed sinus rhythm with the typical $\mathbf{J}$ waves of hypothermia. Ultrasound examination of abdomen showed normal liver, spleen and kidneys, and there were no abnormal lymph nodes or masses. The patient did not agree to undergo bone marrow examination.

She was warmed with a space blanket and rehydrated. Within 24 hours of admission, the temperature rose to $35^{\circ} \mathrm{C}$, and the platelet count rose to $46 \times 10^{9} / 1$. Within 7 days, the platelet count had risen to $307 \times 10^{9} / 1$.

Review of the past medical records showed a consistent association between hypothermia and thrombocytopenia. She had had a total of 12 previous admissions for hypothermia associated with thrombocytopenia since 1981 , and the platelet count always rose to normal when rewarming occurred. Details of the previous admissions are summarized in Table I.

She had had the varicose ulcer since 1981, and it had not healed because of self-neglect. There was no history of alcohol abuse and she had not been treated with phenothiazines. She was found to be hypothyroid in 1985 and had been on adequate replacement therapy since then. She lived alone and paid little attention to matters such as warm clothing and domestic heating. Despite her apparent inability to cope, she had always been happy to return home. It had been concluded that recurrent hypothermia was the result of basic self-neglect. A bone marrow examination was done in 1985 and it 
Table I Relationship between admission temperature, admission platelet count and repeat platelet count: summary of previous admissions

\begin{tabular}{|c|c|c|c|c|}
\hline $\begin{array}{l}\text { Month/ } \\
\text { year }\end{array}$ & $\begin{array}{c}\text { Rectal } \\
\text { temperature } \\
\left({ }^{\circ} \mathrm{C}\right)\end{array}$ & $\begin{array}{c}\text { Platelet } \\
\text { count } \\
(\text { admission }) \\
\left(\times 10^{9} / l\right)\end{array}$ & $\begin{array}{c}\text { Interval } \\
\text { (days) }\end{array}$ & $\begin{array}{c}\text { Platelet } \\
\text { count } \\
\text { (repeated }) \\
\left(\times 10^{9} / l\right)\end{array}$ \\
\hline Oct $/ 81$ & 31.0 & 21 & 6 & $293 \dagger$ \\
\hline $\mathrm{Jan} / 82$ & 31.2 & 10 & 3 & $132 *$ \\
\hline Oct $/ 83$ & 33.6 & 26 & 3 & $140 *$ \\
\hline Jan/85 & 33.2 & 30 & 10 & $397 *$ \\
\hline $\mathrm{Mar} / 85$ & 31.5 & 30 & 1 & $90^{*}$ \\
\hline Jan/86 & 30.0 & 14 & 6 & $520 \dagger$ \\
\hline $\mathrm{Mar} / 86$ & 34.0 & 24 & 4 & $127^{*}$ \\
\hline $\mathrm{Jan} / 87$ & 31.0 & 15 & 8 & Normal* \\
\hline $\mathrm{Feb} / 88$ & 31.2 & 15 & 4 & $145 \ddagger$ \\
\hline $\mathrm{Dec} / 88$ & 32.0 & 12 & 7 & $559 *$ \\
\hline Feb/89 & 32.9 & 7 & 7 & $599 *$ \\
\hline Dec/89 & 31.6 & 39 & 4 & $282 *$ \\
\hline
\end{tabular}

*Only symptomatic treatment; tantibiotics given, but only after platelet count had risen; łantibiotics given at about same time when platelet count was rising.

was normal, with adequate megakaryocytes, as well as normal cellularity of the other two cell lines. Coagulation studies were done on five occasions over the previous 12 admissions, and these were normal at all times except one, where the partial thromboplastin time was slightly prolonged, and fibrinogen and fibrin degradation products were slightly elevated. Repeat and subsequent studies were all normal. Protein electrophoresis had consistently shown slight elevation of all four components of the globulin fraction with reduction of albumin, suggestive of chronic tissue damage. VDRL and TPHA were negative.

\section{Retrospective survey of hypothermia}

We carried out a retrospective survey among patients who were admitted to the Victoria Infirmary between 1986 and 1990. All patients with first or second discharge diagnosis of hypothermia were identified from Scottish Morbidity Record (SMR) statistics for the period of interest. There were a total of 99 admissions in 91 patients with hypothermia. The case records were traced and platelet counts immediately after admission were noted. Nine patients did not satisfy the criteria for hypothermia as their lowest body temperature recorded was above $35^{\circ} \mathrm{C}$. Seven case records could not be traced. The remaining 75 patients, 28 males and 47 females, had temperatures ranging from $25.5^{\circ} \mathrm{C}$ to $35^{\circ} \mathrm{C}$ and platelet counts ranging from 11 to $538 \times 10^{9} / 1$. Only three patients had hypothermia together with thrombocytopenia defined as a platelet count of less than $150 \times 10^{9} / 1$. The first patient had a rectal temperature of $28^{\circ} \mathrm{C}$, and a single platelet count of $108 \times 10^{9} / 1$. She recovered rapidly and was discharged the next day without a repeat count being done. The second patient had a platelet count of $11 \times 10^{9} / 1$. She was admitted following a severe stroke, probably an intracranial haemorrhage, and died a few hours after admission. The third patient is the subject of the above case report.

\section{Discussion}

Animal studies have been done in the past to try to establish the aetiology of hypothermia-induced thrombocytopenia. These studies, using radioactive-tagged platelets, identified the major site of sequestration to be in the liver, and possibly the spleen. ${ }^{5-7}$ The mechanism of sequestration is thought to be due to a number of factors: (a) change in shape of platelets to be more spherical (b) loss of marginal microtubules; (c) the develop ment of pseudopods; (d) an increase in stickines when platelets are chilled to less than $22^{\circ} \mathrm{C}$ in vitro.

This patient was considered to have recurrent thrombocytopenia due to platelet sequestration as a result of hypothermia. Her low platelet count had always responded rapidly to rewarming, and the bone marrow examination done on one occasion failed to demonstrate a reactive marrow that might have explained the rapid increase in platelet count. We have repeatedly failed to identify any other diagnosis that might explain her thrombocytopenia. Protein electrophoresis performed on numerous occasions, the lack of peripheral signs and symptoms, and the preservation of renal and liver function over the years suggest the absence of cryoimmunoglobulins.

\section{Acknowledgements}

The authors would like to thank Ms Barbara Boyd, Senior Information Officer, Management Information Services Division, Greater Glasgow Health Board for her help in retrieving patient information, and also Dr Pat Tansey, Consultant Haematologist, Victoria Infirmary for helpful comments.

\section{References}

1. Vella, M.A., Jenner, C., Betteridge, D.J. \& Jowett, N.I. Hypothermia-induced thrombocytopenia. $J$ R Soc Med 1988 , 81: $228-229$.
2. Burman, J.F. Hypothermia-induced thrombocytopenia (letter). J R Soc Med 1988, 81: 619. 
3. McFadden, J.P. Hypothermia-induced thrombocytopenia (letter). J R Soc Med 1988, 81: 677.

4. Brien, H., Amess, J.A. \& Mollin, D.L. Recurrent thrombocytopenia, erythroid hypoplasia and sideroblastic anaemia associated with hypothermia. Br J Haematol 1982, 51: 451 456.

5. Villalobos, T.J., Adelson, E., Riley, P.A. \& Crosby, W.H. A cause of the thrombocytopenia and leukopenia that occur in dogs during deep hypothermia. J Clin Invest 1958, 37: 1-7.
6. Hessel, E.A., Schmer, G. \& Dillard, D.H. Platelet kinetics during deep hypothermia. J Surg Res 1980, 28: 23-34.

7. Pina-Cabran, J.M. Hepatic and splenic platelet sequestration during deep hypothermia in the dog. Haemostasis 1974, 2: 235.

\title{
Thrombotic thrombocytopenic purpura associated with pregnancy in two sisters
}

\author{
Farouq Alqadah, Mohammed Amin Zebeib and Abdalla S. Awidi
}

Hematology-Oncology Unit, Department of Internal Medicine, Hamad General Hospital, PO Box 3050 , Doha, Qatar, Arabian Gulf

\begin{abstract}
Summary: Two sisters suffered from thrombotic thrombocytopenic purpura late in their first pregnancies. HLA typing of the patients and their immediate family members demonstrated no obvious relationship. Hereditary aspects, association with pregnancy, prognosis and management of pregnant women with TTP are discussed.
\end{abstract}

\section{Introduction}

Thrombotic thrombocytopenic purpura (TTP) is a serious multisystem disease characterized pathologically by widespread intraluminal and subendothelial hyaline thrombi which involve the capillary and precapillary arterioles. ${ }^{1}$ Clinically, $74 \%$ of patients manifest, at any given time during the illness, the triad of thrombocytopenia, microangiopathic haemolytic anaemia and neurological symptoms. Only $40 \%$ of patients present with the classic pentad of renal impairment, high temperature and the triad. ${ }^{2}$ Pregnancy is a wellrecognized condition associated with TTP. ${ }^{3}$ Familial occurrence of TTP is rare, but well documented. ${ }^{4}$ There is one previous report of two sisters who developed TTP during pregnancy. ${ }^{5} \mathrm{We}$ report two further similar cases.

\section{Case reports}

The patients are members of a family of eight siblings, one male and seven females, the offsprings

Correspondence: Farouq Alqadah, M.D., F.A.C.P.

Accepted: 20 August 1992 of non-related Palestinian parents. The first patient, at age 29 years, was in the 38th week of her first pregnancy when she had induction of labour at another hospital in May 1983. The patient was febrile, jaundiced and thrombocytopenic with platelet count $9.0 \times 10^{9} / 1$. She also had Coombs negative haemolytic anaemia. ANA test was negative. She delivered a healthy male baby. Haemolytic anaemia and thrombocytopenia persisted after delivery and failed to respond to steroid therapy. In July 1983 the patient was transferred to a hospital in London. The initial blood count there showed a white blood cell count of $10.4 \times 10^{9} / 1$, platelets $13.0 \times 10^{9} / 1$ and haemoglobin $9.3 \mathrm{~g} / \mathrm{dl}$. Peripheral blood smear showed spherocytes, fragmented and nucleated red blood cells. Bone marrow examination showed increased megakaryocytes. TTP was diagnosed and the patient was started on aspirin, dipyridamole and daily plasma exchange. Her blood count became normal 5 days later, but she relapsed shortly after plasma exchange was discontinued. Subsequently she received plasma infusion and achieved a second remission. The patient was maintained on aspirin and dipyridamole. She has been followed at 